\title{
Impactos psicossociais do trabalho na saúde mental de profissionais em um Centro de Atenção Psicossocial no interior do Ceará
}

\author{
Psychosocial impacts of work on the mental \\ health of professionals in a Psychosocial Care \\ Center in the interior of Ceará
}

\section{Impactos psicosociales del trabajo en la salud mental de profesionales en un Centro de Atención Psicosocial en el interior de Ceará}

\section{Whednagela de Lima Alves' ${ }^{1}$ (1) Tadeu Lucas de Lavor Filho ${ }^{2}$ (1)}

\author{
${ }^{1}$ Escola de Saúde Pública do Ceará (Fortaleza). Ceará, Brasil. whednagelapsicologa@gmail.com \\ ${ }^{2}$ Autor para correspondência. Universidade Federal do Ceará (Fortaleza). Ceará, Brasil. tadeulucaslf@gmail.com
}

\begin{abstract}
RESUMO | OBJETIVO: Este estudo buscou investigar os impactos psicossociais do trabalho na saúde mental dos trabalhadores de um Centro de Atenção Psicossocial-CAPS no interior do Ceará. METODOLOGIA: trata-se de uma pesquisa qualitativa, explicativa, com a análise de oito entrevistas realizadas com os trabalhadores. Através das entrevistas foram criadas as categorias: as dificuldades em realizar o trabalho, conceituação de saúde mental, autocuidado e a relação da saúde mental com a pandemia de COVID-19. Buscou-se articular a Saúde Mental e a relação que o trabalho estabelece na vida das pessoas. RESULTADOS: observou-se que os trabalhadores investigados não reconhecem os impactos que o trabalho reflete na sua vida cotidianamente, assim como, apresentam dificuldades de praticar estratégias de autocuidado. CONCLUSÃO: com isso, ressalta-se a importância das práticas de autocuidado para manutenção da saúde mental desses trabalhadores, bem como, a intensificação de estratégias de saúde do trabalhador pelas políticas públicas.
\end{abstract}

PALAVRAS-CHAVE: Saúde mental. Saúde dos trabalhadores. Impactos psicossociais. Autocuidado.

ABSTRACT | OBJECTIVE: This study sought to investigate the psychosocial impacts of work on workers' mental health at a Psychosocial Care Center-CAPS in the interior of Ceará. METHODOLOGY: This is a qualitative, explanatory research, with the analysis of eight interviews carried out with workers. Through the interviews, the following categories were created: difficulties in performing the work, the conceptualization of mental health, self-care, and the relationship between mental health and the COVID-19 pandemic. We sought to articulate Mental Health and the relationship that work establishes in people's lives. RESULTS: it was observed that the investigated workers do not recognize the impacts that work reflects on their daily lives and have difficulties in practicing selfcare strategies. CONCLUSION: With this, the importance of self-care practices for maintaining the mental health of these workers is highlighted, as well as the intensification of worker health strategies by public policies.

KEYWORDS: Mental health. Workers' health. Psychosocial impacts. Self-care.

Como citar este artigo: Alves, W. L., \& Lavor Filho, T. L. (2021). Impactos psicossociais do trabalho na saúde mental de profissionais em um Centro de Atenção Psicossocial no interior do Ceará. Revista Psicologia, Diversidade e Saúde, 10(3), 429-441. http://dx.doi.org/10.17267/23173394rpds.v10i3.4055 
RESUMEN | OBJETIVO: Este estudio buscó investigar los impactos psicosociales del trabajo en la salud mental de los trabajadores de un Centro de Atención Psicosocial-CAPS en el interior de Ceará. METODOLOGíA: se trata de una investigación cualitativa, explicativa, con el análisis de ocho entrevistas realizadas a trabajadores. A través de las entrevistas se crearon las siguientes categorías: dificultades en el desempeño del trabajo, conceptualización de la salud mental, autocuidado y la relación entre la salud mental y la pandemia COVID-19. Buscamos articular la Salud Mental y la relación que el trabajo establece en la vida de las personas. RESULTADOS: se observó que los trabajadores investigados no reconocen los impactos que el trabajo refleja en su vida diaria, así como tienen dificultades para practicar estrategias de autocuidado. CONCLUSIón: Con ello, se destaca la importancia de las prácticas de autocuidado para el mantenimiento de la salud mental de estos trabajadores, así como la intensificación de las estrategias de salud de los trabajadores por parte de las políticas públicas.

PALABRAS CLAVE: Salud mental. Salud de los trabajadores. Impactos psicosociales. Autocuidado.

\section{Introdução}

O artigo trata-se de um estudo realizado para conclusão de Residência Multiprofissional em Saúde Mental vinculado a Escola de Saúde Pública do Ceará, que teve como objetivo avaliar os impactos psicossociais do trabalho na saúde mental dos trabalhadores de um Centro de Atendimento Psicossocial (CAPS) em uma cidade no interior do Ceará. A proposta deste estudo é justificada pela necessidade de discutir a produção de cuidado em saúde mental entre os profissionais do CAPS, sobretudo em tempos de pandemia de Covid-19.

A conceituação de Saúde mental não é algo definitivo ou restrito, tendo em vista que se refere ao equilíbrio emocional e psicológico de cada sujeito, o que sofre interferências de acordo com a cultura e processos subjetivos individuais. Logo, pode-se dizer, que a saúde mental se apresenta na capacidade de resposta as demandas sociais cotidianas, por meio das suas habilidades emocionais e cognitivas, proporcionando um bem-estar e equilíbrio ao sujeito (Lucca, 2017).

Contudo, compreende-se que o homem não existe no mundo sozinho, e que suas interações sociais definem como cada um vivencia seu mundo. Diante das necessidades existentes encontra-se o trabalho, que pode se apresentar em dois sentidos, seja para realizações de consumo e obrigações básicas de sobrevivência, seja para autorrealização. Neste sentido, destaca-se a importância que o trabalho assume na construção da identidade e subjetividade de cada ser, interferindo diretamente na sua saúde, visto que aqui entende-se corpo e mente como indissociáveis (Campos, 2017).

A Saúde Mental enquanto campo de atuação profissional tem se mostrado muito complexa, pois é demandado que o trabalho seja desenvolvido a partir de novas tecnologias do cuidado, bem como um olhar horizontalizado para o sujeito (Ribeiro et al., 2018). Ao se referir a tecnologias do cuidado, aqui, trata-se de todo os envolvidos para fazer saúde, seja o maquinário, seja o trabalho humano que irá operacionalizar todos os serviços. Logo, para a saúde apresenta-se três tipos de tecnologias, as "tecnologias dura", "tecnologias leve-dura" e "tecnologias leves". Ressaltando as tecnologias leves como qualidades a serem adquiridas pelos profissionais pra lidar melhor com o adoecimento, exemplos dessas são o acolhimento, escuta qualificada, estabelecimento de vínculo e desenvolvimento de autonomia.

Essas novas exigências, tem se justificado com a mudança desenvolvida para fazer saúde, saindo de um modelo asilar e hospitalocêntrico para um modelo psicossocial, onde a cultura, o social e o psíquico são cuidados de forma integral, deixando os aspectos orgânicos de serem unicamente centrais (Silva et al., 2015).

Essa nova forma de se pensar e fazer saúde mental surge com a superação do modelo manicomial, o qual se estrutura nas políticas de saúde do Brasil que se construíram através de marcos teóricos e políticos como, a $8^{a}$

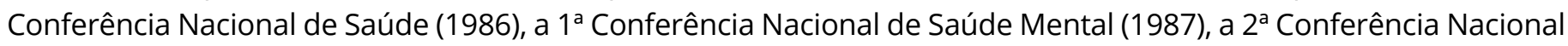
de Saúde Mental (1992), e a $3^{\text {a }}$ Conferência Nacional de Saúde Mental (2001). Desde então, tem acontecido a reestruturação da assistência psiquiátrica no país, onde os hospitais psiquiátricos foram substituídos gradativamente pelas redes de atenção à saúde mental, Centros de Atenção Psicossocial (CAPS), leitos psiquiátricos em hospitais gerais, residências terapêuticas, e outros serviços que atendam às necessidades de cada município (Hirdes, 2009). 
Para tanto, é necessário compreender o CAPS como equipamento central e referência do novo modelo de atenção à Saúde mental após a reforma psiquiátri$\mathrm{ca}$, que é instituído por uma equipe multiprofissional disposta a atender pessoas em sofrimento psíquico decorrentes de transtorno mentais psicóticos ou uso abusivo de substâncias químicas, sendo diferenciado a partir das suas modalidades e demandas (Portaria n. $3.088,2011)$.

Vale destacar que este equipamento faz parte da Rede de Atenção Psicossocial - RAPS, e desenvolve-se como um articulador para promoção de saúde e desenvolvimento de autonomia desses sujeitos, trabalhando em conjunto com as equipes de Saúde da Família e agentes comunitários de saúde, buscando o funcionamento em rede bem como nos territórios de atuação (Ministério da Saúde, 2015).

Ainda que o modelo de atenção psicossocial exija profissionais capacitados e comprometidos, estes, enfrentam grandes dificuldades em suas experiências cotidianas, visto que, existe um despreparo nas práticas de atendimentos humanizados assim como ausência de subsídios (financeiros, capacitações para atendimentos e melhoria nos recursos humanos) que se faça compreender esse novo modelo (Ribeiro, 2015).

Marqueze e Moreno (2005) destacam que a satisfação dentro das suas atividades laborais interfere de forma direta na vida pessoal do sujeito trabalhador e que afeta comportamentos, a saúde e o bem-estar, dessa forma, compreendem-se que para fazer saúde mental é necessário que esse profissional esteja desempenhando sua função de forma satisfatória bem como cuidando de si, para que isso não interfira no seu ambiente de trabalho e possa consequentemente prejudicar o serviço ofertado ao usuário.

Realizada essa discussão inicial, ressalta-se a importância do equipamento CAPS para a Rede de Atenção à Saúde e os serviços derivados de políticas intersetoriais, bem como o destaque para os profissionais que trabalham com saúde mental. Tendo em vista, que ainda existe dificuldades de comunicação em Rede que culminam na sobrecarga de trabalho desses profissionais, fica evidente a relevância de investigar como profissionais que lidam diariamente nessa área, são afetados pelo seu trabalho.
Desse modo, este artigo é fruto de uma pesquisa com profissionais do CAPS de um município do interior do Ceará que se espera fomentar um diálogo para compreensão de estratégias que aliviem os impactos psicossociais sofridos por esses profissionais. Visando ainda, que o estudo sirva de aporte teórico para gestão municipal compreender os sofrimentos dos seus trabalhadores, podendo assim, realizar ajustes nas condições de trabalho, carga horárias, infraestrutura, remuneração, bem como, pensar a elaboração de portarias que garantam e assegurem os direitos dos trabalhadores quanto a sua saúde mental.

\section{Metodologia}

O presente artigo é uma pesquisa explicativa, exploratória de natureza qualitativa que teve como delineamento metodológico a natureza aplicada, definida por Gil (2010) como o método de pesquisa que visa a produção de conhecimento por meios práticos, objetivando a resolução de problemas específicos. A pesquisa explicativa busca reconhecer os motivos que contribuem ou determinam que tal acontecimento venha a ocorrer (Gil, 2010).

O presente estudo teve como lócus de pesquisa o CAPS em uma cidade no interior do Ceará, localizado na região do Cariri. O equipamento de Saúde durante o estudo estava funcionando durante a manhã das $07: 30$ as $11: 30$ e a tarde das $13: 30$ as 17:30 de segunda a sexta feira. Funcionava em uma casa alugada, contendo 2 consultórios (um da enfermagem e o outro eram organizados os dias para atendimentos médicos e psicológicos), uma sala para coordenação, por vezes utilizada para atendimentos psicológicos devido a presença da psicóloga do equipamento e a profissional residente. Apresentava ainda, espaço amplo para realizações de grupos terapêuticos.

O estudo foi contemplado pelos trabalhadores que atuam no CAPS, em suas diversas funções. No primeiro momento foi realizado o contato com a Coordenadora do equipamento de saúde objetivando a autorização da pesquisa, para que posteriormente fosse realizado entrevistas semiestruturadas com os funcionários. Totalizaram 08 (oito) entrevistados, sendo 05 (cinco) mulheres e 03 (três) homens. 0 período de realização do estudo foi de setembro a novembro de 2020. 
Um dado importante quanto aos entrevistados, é que não foi possível realizar a entrevista com a médica psiquiatra devido a sua alta demanda de atendimentos, e pouca disponibilidade para continuar no serviço após seus atendimentos. Outras duas pessoas não se sentiram à vontade para participar da entrevista, o porteiro por acreditar que não saberia responder as perguntas e a auxiliar de serviços gerais, pois só estava trabalhando no serviço há um mês.

Quanto aos procedimentos, tratou-se de uma pesquisa participante, onde ocorreu relação direta entre entrevistados e pesquisador, bem como, pela pesquisadora ser profissional residente no serviço atuando de forma direta por dois anos com a equipe.

A coleta de dados foi realizada através de um roteiro de entrevista semiestruturada, que se caracteriza por ser mais flexível, podendo ser ajustada de acordo com a fala do sujeito e realizada mediante a presença do entrevistado e do entrevistador. Com isso, foi elaborado um plano de entrevista com o intuito de não perder o foco e atingir aos resultados esperados. Logo, esse plano apresentou as mesmas questões de entrevistas para todos os sujeitos, o que não necessariamente foi respondido seguindo a linearidade das perguntas, pois, permitiu que a fala pudesse surgir livremente (Kauark et al., 2010).

A entrevista foi gravada mediante autorização dos participantes. O roteiro de entrevista teve como estrutura blocos de perguntas relacionadas as experiências de trabalho no CAPS, autocuidado dos sujeitos entrevistados, percepção de saúde mental, as adversidades e pontos positivos encontrados no campo de trabalho, e percepção sobre o trabalho durante $o$ isolamento social frente a pandemia de Covid-19. As entrevistas foram realizadas no ambiente de trabalho, durante os intervalos de atendimentos dos trabalhadores, tal horário foi acordado mediante a indisponibilidades dos mesmos de ficarem após o horário de trabalho.
Todos os participantes foram informados sobre os objetivos e metodologia utilizada no estudo, garantindo-lhes discrição e o direito de recusar-se a participar ou solicitar sua exclusão a qualquer momento, sem prejuízos de qualquer natureza. Antes da coleta de dados os participantes assinaram o Termo de Consentimento Livre e Esclarecido (TCLE), que comprovou sua aceitação em participar da pesquisa e autorizou a gravação da entrevista bem como a divulgação e publicação dos resultados. Ressalta-se, ainda, que o presente estudo foi aprovado pelo Comitê de Ética da Escola de Saúde Pública do Ceará (Número do parecer: 4.068.887. CAAE: 31524020.8.0000.5037).

Para contemplar a análise foi realizada inicialmente a transcrição por completa dos áudios gravados com as respostas do roteiro de entrevista. Tais transcrições foram feitas à medida em que foram se realizando as entrevistas pelo próprio pesquisador, que teve o cuidado em realizá-lo com a maior fidedignidade possível, atentando-se ao uso da pontuação adequada para que o material transcrito não se diferenciasse com tanta percepção do momento vivenciado (Demartini, 1988). Tendo em vista o método da autora Demartini (1988), foram realizados fichamentos e selecionados categorias a serem trabalhadas.

Quanto a seleção de categorias e análise das entrevistas, foi realizada através do Software Atlas.ti 9, que possibilitou uma sistematização do conteúdo das entrevistas de acordo com as categorias criadas pela pesquisadora no software, e ao final emitiu-se um relatório com os dados que contemplaram os Resultados e Discussão do presente artigo. Para explicitar a sistematização das categorias de análise das entrevistas, apresentamos a seguir o mapa esquemático dos códigos analíticos de sentido no Atlas Ti (figura 1). A sessão de discussão a seguir trata de apresentar como a relação entre categorias abordada na figura 1. 
Figura 1. Diagrama das categorias de sentido construída para desenvolvimento dos resultados e discussões a partir das materialidades de campo

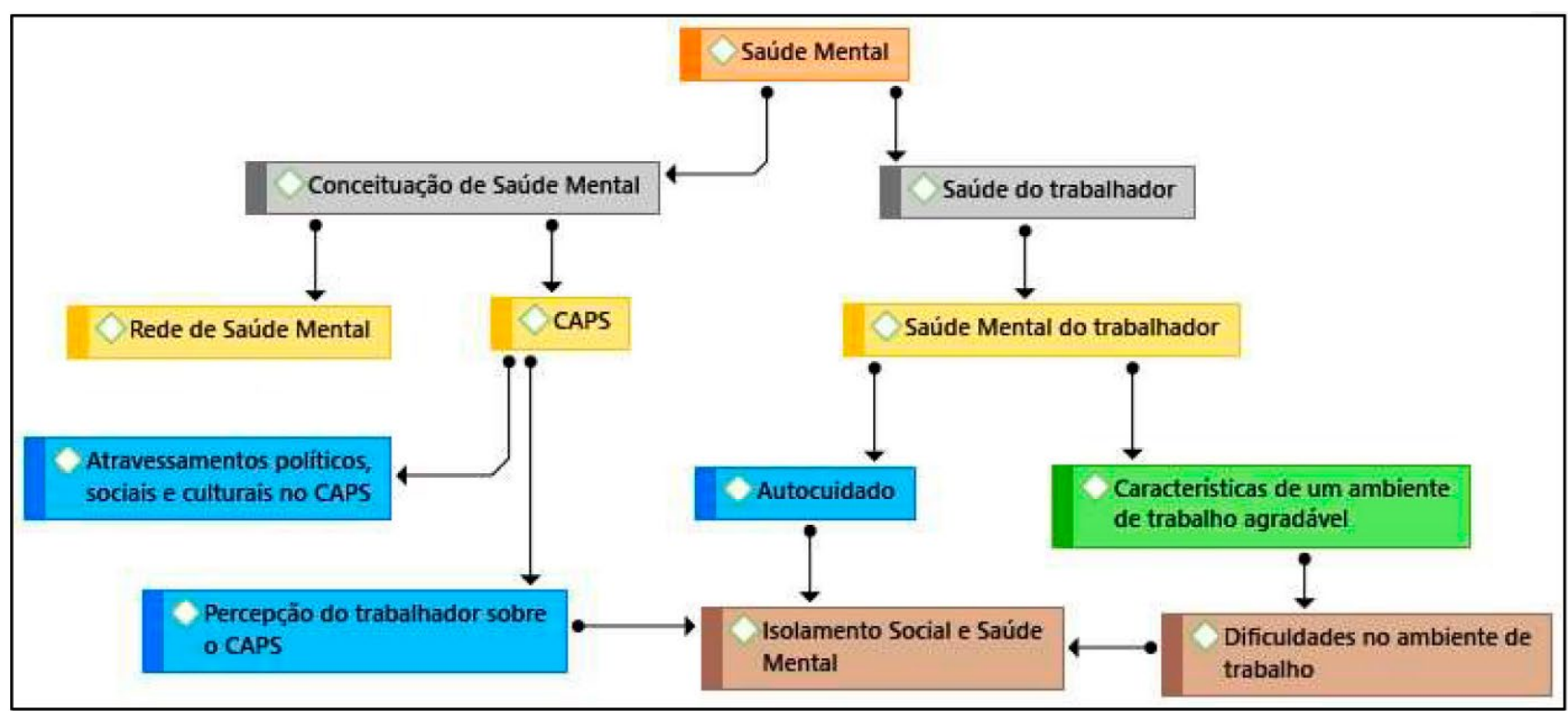

Fonte: Os autores (2021).

Por fim, para garantir o sigilo dos participantes da pesquisa, os sujeitos foram identificados pela representação de $\mathrm{P}$ (pessoa), seguido do número da sequência das entrevistas (do número 01 ao 08).

\section{Resultados e discussão}

Para a análise e discussão foram desenvolvidas quatro categorias que contemplam o debate dos objetivos do trabalho. As categorias de análise apresentadas didaticamente para a construção da discussão analítica estão divididas em: a percepção do trabalhador sobre a atuação do CAPS; atravessamentos do autocuidado por questões sociais, políticas e culturais dos trabalhadores do CAPS; o ambiente de trabalho como agente no processo saúde/ doença do trabalhador e pandemia COVID/19 e saúde mental.

\section{A percepção do trabalhador sobre a atuação do CAPS}

Novas dimensões da saúde foram visionadas em órgãos políticos e nas leis que os regem. Como exemplo, podemos citar o advento das tecnologias, das micropolíticas e de novas técnicas de intervenção psicossocial nos hospitais e nas redes gerais de atenção à saúde (Wetzel et al., 2008). Através desta e de outras correntes de inovação, observou-se a necessidade de uma reorientação do modelo de atenção à saúde, não só a deixando estrita apenas ao gabinete, mas também a direcionando às comunidades (Vieira et al., 2010).

Objetivando essa melhoria, a lei no 10.216 de 2001, que regulamenta a Política de Saúde Mental, trouxe inúmeros benefícios aos modelos das práxis profissionais nos mecanismos de saúde mental no Brasil (Pinho et al., 2008). Com isso, novas perspectivas de crescimento foram esplanadas, debatidas e trabalhadas nas mais diversas concepções de saúde existentes. 
Imerso nesse modelo teórico-prático de atenção à saúde, e junto a reforma psiquiátrica, surgem os Centros de Atenção Psicossocial (CAPS), que tem como objetivo principal, segundo Alves (2009), proporcionar alternativas de apoio a sujeitos em condição de vulnerabilidade psíquica e social através do conhecimento, acolhimento e modificação das práticas de convívio social de uma determinada comunidade.

Durante as entrevistas os profissionais ressaltaram a importância do serviço do CAPS principalmente para suprir as vulnerabilidades presentes no município quanto a assistência em saúde, o que se afirma na fala de uma das entrevistadas:

"Eu acho que é pra ter um apoio para as pessoas que não tem condição de ter acesso a serviço particular de psiquiatra, psicólogo, essas coisas, aí eu acho que é importante" (P02).

Ainda sobre a percepção dos entrevistados acerca da importância do CAPS no município, apresenta-se duas sequências discursivas:

"É muito importante né, é um trabalho de rede e que assim, a demanda de saúde mental tem só crescido... E que é muito bom né, tem tido um resultado positivo, tem atendido um grande número de pessoas, apesar das dificuldades que tem." (P01).

"É de grande utilidade, porque tem muitas pessoas carentes que necessita do serviço do CAPS" (P05).

O que pode se observar é que os trabalhadores reconhecem o serviço como importante para a população bem como, entendem que o seu funcionamento deve ocorrer através da Rede de Saúde, acontecendo a articulação do serviço de acordo com as demandas de cada paciente, se fazendo necessário que as Estratégias de Saúde da Família - ESFs se comuniquem com o Núcleo Ampliado de Saúde da Família e Atenção Básica- NASF- AB e CAPS.

"É importante o trabalho do CAPS aqui, porque existe uma alta demanda no município, o que eu acho que falta é um pouco de direcionamento das demandas para seus órgãos específicos." (P08)
Vieira et al. (2010) afirma que os CAPS aparecem como um dos elos da rede de atenção básica à saúde e são constituintes primordiais das redes de saúde mental, conseguintes da influência das lutas antimanicomiais. Estes mecanismos aparecem como grande alternativa à substituição gradual dos manicômios e agem com um propósito final de inutilização destes sanatórios, contrariando, portanto, um modelo hospitalocêntrico que era anteriormente pregado em nossa sociedade, mas que se entende que mesmo com as mudanças esse modelo manicomial atravessa a sociedade disfarçadamente.

O que fica claro nessa categoria é que todos os profissionais conseguem entender a importância do CAPS para seu município, destacando que os serviços prestados atendem de uma forma positiva as vulnerabilidades sociais. Contudo, ressalto aqui, enquanto profissional residente também desse serviço, que muitas das demandas atendidas era realizada com um grupo que poderia realizar consultas particulares e por vezes, por terem conhecimentos na gestão municipal, eram atendidos de forma rápida e sem precisar aguardar a disponibilidade de agenda dos profissionais.

O que tão logo, poderia evidenciar a alta demanda de atendimentos, a má organização e distribuição na rede de saúde e a sobrecarga dos profissionais do CAPS. Já destaco aqui, o receio dos profissionais em falar de forma fidedigna durante as entrevistas sobre o real funcionamento do serviço mediante as vagas ocupadas, pois apenas um dos entrevistados eram concursados, logo, levanto o questionamento das respostas terem sido simplistas frente ao medo de perderem o seu cargo, posto que estávamos em ano político, e municípios de pequenos portes tendem a sofrerem repressões nesse sentido.

Lembro de uma fala muito marcante, onde um dos profissionais me parabenizou pela iniciativa do trabalho e relevância da temática, porém me pediu para não gravar, pois, não se sentiria confortável em falar sobre as possíveis dificuldades dentro do seu trabaIho tendo em vista que estava ali como contratado e teria que desempenhar bem o seu papel para garantir o emprego. 
O que anuncia o receio de falar sobre o que poderia ser melhorado no ambiente de trabalho, o que por vezes é a justificativa de um trabalho precarizado e adoecedor, é preferível aceitar e ter onde trabalhar, do que reivindicar e correr o risco de ser demitido.

\section{Atravessamentos do autocuidado por questões sociais, políticas e culturais dos trabalhadores do CAPS}

Nessa categoria buscou-se investigar as percepções dos trabalhadores acerca do autocuidado e como este reverbera na sua saúde mental. Fica perceptível a dificuldade dos trabalhadores em reconhecer a relação entre esses dois termos e o trabalho. Apesar dos entrevistados serem trabalhadores da área de saúde mental, observou-se uma dificuldade em conceituar e legitimar que a saúde mental dos mesmos se encontra sobrecarregada e precisando de cuidados.

"É você cuidar de você mesmo, cuidar da também da sua saúde mental, cuidar também do seu bem-estar, e do seu ambiente de trabalho, cuidar da sua saúde em geral, física, mental, e também ter um ambiente que Ihe favoreça a se sentir bem. Mas ultimamente não tenho feito nada para cuidar da minha" (P01).

"É cuidar de si próprio né? Acho que é isso. (Risos) Mas eu não tenho feito isso não (risos)" (P02).

É justificável que mesmo com a melhoria e transformação dos atendimentos multidisciplinar no Sistema Único de Saúde (SUS), ainda se apresentem contrariedades na maioria das vezes para os profissionais estabelecerem a relação entre saúde mental e trabalho, e isso se aplica aos profissionais que cuidam de trabalhadores já adoecidos, assim como do próprio trabalhador reconhecer seu adoecimento e buscar ajuda. Isso porque, pode-se dizer que a Saúde do trabalhador é um campo ainda recente no Brasil (Bottega \& Merlo, 2017).

A seguir duas falas discursivas dos entrevistados sobre as práticas de autocuidado realizadas por eles, com objetivo de manter a saúde mental estável no trabalho e nas suas relações sociais, e que são representadas por suas singularidades;
"Autocuidado é a atenção necessária a mim mesmo considerando o cuidado com o corpo e a mente. No trabalho mantenho a calma, paciência e profissionalismo. Em casa reflito sobre a importância da vida, do trabalho e da interação com as pessoas. Também busco fazer coisas que me é possível fazer e que de alguma forma me faça se sentir bem" (P06).

"É ter uma atenção redobrada, se prevenir e ter agilidade no que você tá fazendo na vida. Procuro não discutir com ninguém, ter calma, paciência e não dá muita atenção e ouvidos a tudo que o povo fala. E aí busco fazer plantação, aguar as plantas e cuidar dos meus cachorros, que é o que me faz bem" (P05).

Pensando nesse tema de saúde, a trajetória da Saúde do trabalhador no Brasil teve início decorrente do crescimento de trabalhadores nas indústrias e suas reivindicações para melhorias no âmbito laboral que ocorreu a partir dos anos de 1970 (Gomez et al., 2018). Em decorrência dos fatos, o Sindicato dos Trabalhadores Químicos e Petroquímicos do $A B C D$ no Estado de São Paulo, obteve forte influência para criação da Secretaria de Estado da Saúde (SES), em 1984, o que adiante permitiu à ascensão de Programas de Saúde do Trabalhador (PST) em vários Estados (Lacaz, 2007).

Diante da evolução nesse campo, vale lembrar que nesse período não se tinha o Sistema Único de Saúde (SUS), logo, as intervenções realizadas eram a nível assistencial, o que houve alteração com a VIII Conferência Nacional de Saúde onde afirmava que para se ter acesso a saúde era necessário que o trabalhador compreendesse seu processo laboral e o realizasse em condições dignas (Gomez et al., 2018).

Com o reconhecimento da necessidade de melhorias no campo de saúde do trabalhador elabora-se o conceito de Saúde do Trabalhador (ST) caracterizada pelas ações de promoção, prevenção, recuperação e reabilitação da saúde desse grupo (Melo et al., 2019). Para garantia e operacionalização desse direito o Ministério da Saúde cria em 2002, a Portaria GM Nº 1679 de 19 de Setembro de 2002, que dispõe sobre a estruturação da Rede Nacional de Atenção Integral à Saúde do Trabalhador (RENAST). 
A RENAST passa a ser a principal forma de organização da ST no SUS, ou seja, é através dela que haverá a articulação entre a rede de Atenção Básica e no Programa de Saúde da Família (PSF), a Rede de Centros de Referência em Saúde do Trabalhador (CEREST) e ações na rede assistencial de média e alta complexidade do SUS (Portaria n. 1679, 2002).

No município o qual a pesquisa foi realizada não consegui observar estratégias facilitadoras e de cuidado para com a saúde dos trabalhadores do CAPS. Tendo em vista que por lei, a gestão municipal de saúde deve oferecer atividades e vivencias que elucidem a saúde do trabalhador, isso não foi observado durante a pesquisa.

Durante a vivência no CAPS enquanto residente multiprofissional estive inserida nesse serviço por dois anos, e algumas vezes nos diálogos cotidianos e informais haviam relatos de profissionais adoecidos que não estabeleciam relação causal com o trabalho, logo não buscavam ajuda pelos meios legais que lhe são garantidos. Dentro de nossas análises, esta escuta informal permitiu problematizarmos essa não percepção da relação de saúde mental e o ambiente de trabalho.

Outro fator a ser apontado como hipótese de adoecimento desses trabalhadores, é que, em sua maioria os cargos que ocupavam eram a nível de contratação, sendo apenas dois concursados. Logo, estavam submetidos a trabalhar pelas condições impostas pela gestão municipal, não podendo dessa forma se perceberem adoecidos ou preocupados com sua saúde mental e as práticas de autocuidado, visto que, necessitavam continuar nos empregos. Uma vez que isso condiciona não apenas a precariedade da oferta de serviço por uma equipe longitudinal, mas também um ambiente de trabalho que fica à espreita dos comandos e receios da gestão municipal.

\section{O ambiente de trabalho como agente no processo saúde/doença do trabalhador}

Ao contextualizar o termo "trabalho", Dejours (1993) diferencia condições de trabalho e organização do trabalho. Caracteriza condições de trabalho as funções relacionadas com as exigências físicas do trabalhador, bem como suas condições de segurança e higiene no seu posto de trabalho. O que infere dizer, que as condições de trabalho lesam a saúde corporal do trabalhador.
Por sua vez, Azevedo e Lobo (2013) relatam que a organização do trabalho exerce maior influência ou pressão sobre o aparelho psíquico, pois através dele que se organizam o real significado do trabalho para os sujeitos. O que tem se observado é que o mundo do trabalho vem sofrendo constantes mudanças o que tem atingido diretamente a vida dos trabalhadores, tendo em vista que, os mesmos são cobrados a serem cada vez melhor, não importando suas condições de trabalho. Logo, o trabalho pode ser considerado fonte de prazer e satisfação para os sujeitos, mas também um fator significativo para o adoecimento humano (Cordeiro et al., 2016).

Diante do exposto observa-se como a saúde do trabalhador é influenciada pelo seu campo de atuação, isso se confirma mediante a significação que as pessoas atribuem ao seu trabalho, dessa forma se deixando afetar pelo meio que está inserido. Com isso, os lugares, tempo e ações de trabalho são fatores em potencial que atingem a saúde dessa população (Resende, 2019).

Em consonância com o autor supracitado, a seguir apresentam-se duas sequências discursivas dos trabalhadores do CAPS quanto ao significado das suas funções no ambiente de trabalho:

"Eu acho muito importante e me sinto bem e acho que é gratificante, porque de qualquer forma além de você está fazendo seu trabalho, trabalhando em sua área, você também percebe que ajuda muitas pessoas" (P01).

"No caso do CAPS, pra mim, eu me sinto realizada porque é uma área que eu gosto, me sinto bem. Eu posso dizer que é importante você ajudar, você mediar um serviço, de você melhorar até mesmo autoestima de um paciente, enfim, de melhorar a saúde mental de uma pessoa num todo" (P07).

De forma unânime todos os entrevistados se reconhecem como trabalhadores desse equipamento de forma satisfatória, tecendo elogios ao equipamento e a função desempenhada, apresentando poucas dificuldades para realizarem seu trabalho e se manterem de forma saudável no seu exercício. Quanto ao fato de serem reconhecidos também como seres que precisam de cuidados para lidar com o trabalho, apenas um entrevistado trouxe de forma explícita ao falar sobre sua função. 
"Apesar de me sentir útil nos diversos serviços que faço nos atendimentos, percebo o quanto também eu preciso de cuidados. Que preciso estar bem comigo mesmo para que possa fazer um bom trabalho" (P06)

Parte da experiência de ter vivenciado a coleta de dados enquanto pesquisadora participante, pois ressalto aqui, que estive trabalhando com essa equipe, é que diariamente ouvia queixas das condições de trabalho que estavam submetidos, e o quanto isso era exaustivo e desmotivante para o profissional, seja pelas questões de infraestrutura (ausência de materiais de papelaria, dificuldades ao acesso à internet, falta de água no prédio, ausência de ventiladores para toda a equipe), baixa remuneração ou falta de reconhecimento profissional pela gestão. Apesar das dificuldades constatadas pela pesquisadora no campo de pesquisa, elas não foram descritas em profundidade pelos participantes, o que pode ser observado nos relatos seguintes:

"Não, pra realizar a minha função não, a realidade que eu percebo, é do tratamento, que eu acredito que não seja uma realidade só do município, e sim do sistema público, desse tratamento alcançar a máxima dele para os pacientes, por dificuldades na rede pública" (P03).

"Não, eu não percebo nenhuma dificuldade não. Às vezes é, falta algumas coisas né que a gente gostaria que tivesse, mas não tem, e é isso" (P01).

"Não, só as vezes, quando ficam chamando um do lado e outro de outro, eu fico meia perdida, porque eu não consigo fazer assim minhas coisas, se tiver várias coisas ao mesmo tempo, mas só isso mesmo". (P02).

Ou seja, eles identificam que há algo a ser melhorado, contudo não conseguem ou não quiseram verbalizar os motivos reais, trazendo como dificuldade o serviço de saúde de uma forma geral ou uma dificuldade de relacionamento intrapessoal, não sendo ressaltado aqui, os motivos que verbalizavam no nosso dia a dia durante a realização do trabalho.

Apesar de que, na pesquisa os sujeitos entrevistados não estão afetados ou não percebem o seu trabalho como determinante e influenciador da sua saúde e de suas relações, os autores a seguir, discutem a premissa que o sujeito é sim afetado pelo seu trabalho, perpassando pelas suas instâncias emocionais, físicas e sociais, podendo se deixar impactar por eles.
Resende (2019) enfatiza que a saúde do trabalhador sofre fortes influências mediante o seu campo de atuação, frente a significação que as pessoas atribuem ao seu trabalho, dessa forma se deixando afetar pelo meio que está inserido. Com isso, os lugares, tempo e ações de trabalho são fatores em potencial que atingem não somente a saúde física, mas também a saúde mental dessa população

Fonseca (2017) também discute aspectos que reverberam na ST, tais como a forma de se relacionar com as pessoas no ambiente laboral, a maneira que a chefia exerce sua função, remuneração, reconhecimento profissional entre outros. Situações de estresse vivenciadas nesse ambiente como carga horária excessiva, falta de clareza na comunicação, delegação de funções incoerente, e assédio moral e sexual estão diretamente relacionados ao alto índice de transtornos mentais em trabalhadores.

Quanto a presente pesquisa, não foi possível estabelecer uma relação de adoecimento nesses profissionais pelo fato de trabalharem diretamente com demandas de saúde mental. Ou seja, os profissionais pesquisados, não sentem dificuldades em trabalhar com transtornos mentais diariamente, e também não se deixam afetar emocionalmente pelos inúmeros transtornos e históricos de vulnerabilidade dos pacientes que acompanham. Dessa forma, aqui, afirma-se que o fato de trabalhar com saúde mental não se caracteriza como um fator determinante para adoecimento mental dos trabalhadores. No entanto observa-se um desgaste emocional ao enfrentar as dificuldades do dia a dia, as quais não foram citadas por eles (tais como, falta de água, dificuldade com alimentação para os pacientes, falta de internet, falta de material para oficinas terapêuticas entre outras), por hipóteses já levantadas na primeira categoria dessa sessão.

\section{Pandemia COVID-19 e Saúde Mental dos trabalhadores}

A pandemia de COVID-19 teve início em dezembro de 2019 na China, onde foi identificado um novo coronavírus, o SARS-CoV-2 que se apresenta desde infeções assintomáticas a quadros graves. Os sintomas podem variar de um resfriado, a uma Síndrome Gripal-SG (presença de um quadro respiratório agudo, caracterizado por pelo menos dois dos seguintes sintomas: 
sensação febril ou febre associada a dor de garganta, dor de cabeça, tosse, coriza) até uma pneumonia severa. E o seu contágio é disseminado de uma pessoa para outra, através de contatos próximos como o aperto de mão, tosse, gotículas de saliva, espirros ou a troca de objetos contaminados (Ministério da Saúde, 2020).

A pesquisa foi realizada em um momento crítico da saúde pública, pois vivenciamos uma pandemia de um novo coronavírus no nosso país, portanto, não poderia deixar de entender como esses profissionais estavam lidando com tal situação, visto que, a saúde mental tem sofrido fortes impactos diante do isolamento social, medo do novo, adaptação ao vírus para sobrevivência, bem como mudanças de hábitos. Ao serem questionados acerca da sua saúde mental frente a pandemia, obteve-se as seguintes respostas.

"De certa forma tem afetado, primeiramente pela insegurança, uma pandemia dessa não deixa de gerar um pânico, a gente fica mais vigilante principalmente em relação aos pacientes como a gente é conhecedor, eu falo como enfermeiro. E você fica se vigiando, além de tá ali se monitorando, você também fica ali monitorando os outros, pra ver se eles não estão fazendo algo que possa contrair o vírus" (P01).

Percebo que as minhas insônias tem aumentado, estou apresentando muitas dificuldades para dormir(P08).

\section{"Me sinto um pouco apreensiva com a incerteza do} amanhã" (P04).

Ser profissional de saúde diante de uma pandemia exige ainda mais do profissional, é demandado cuidados com a prevenção do contágio do vírus e ao mesmo tempo é preciso continuar exercendo sua função, é ter que retornar para casa depois de um dia de trabalho com a incerteza de ter sido ou não infectado e transmitir o vírus COVID-19 para os familiares. Esta realidade também coloca em foco a dimensão e a essencialidade do serviço especializado de saúde mental, que é o CAPS, mesmo diante de um cenário de crise (Oliveira et al., 2020).
"Com relação ao trabalho tenho preocupações no sentido de ter que tá mantendo contato com as pessoas, sem ter a certeza que essas pessoas estão fazendo o isolamento da maneira correta e a higiene da maneira que é indicada fazer. Então a angustia é mais nesse sentido de ter que tá mantendo contato com as pessoas diante dessa incerteza. E nas minhas relações sociais e pessoais fica o vazio da falta da rotina que tinha, das coisas que costumava fazer (P03)

O que se tem de certeza atualmente é que a forma mais eficácia de prevenção contra essa doença é o isolamento social, o uso de máscaras e a higienização do corpo e de materiais utilizados no dia a dia. Frente a isso, muitos serviços foram paralisados, visando a minimização do contágio com o a diminuição de circulação de pessoas. Cito aqui, diminuição, porque alguns serviços vistos como essenciais não puderam inabilitar-se, como é o caso da saúde, mesmo em riscos os profissionais estiveram na linha de frente do cuidado desde o início, o que apresenta impactos no trabalho e na vida social desses sujeitos.

"No meu trabalho não, mas na minha família interferiu $\mathrm{sim}$. Porque eu ficava com medo, que não queria que as pessoas saíssem de casa, e eles não respeitavam e então eu ficava estressado, mas não queria falar para não brigar dentro de casa" (P05).

Um pouco inseguro apesar dos cuidados. Me sinto frágil e receoso, fico com a mente afetada por conta das restrições nos atendimentos (P06).

Visto isso, são diversos os fatores que tem interferido na saúde mental dos trabalhadores frente a essa pandemia. O medo de contrair o vírus e transmitir aos entes queridos, a insegurança do amanhã, a dificuldade de adaptação ao novo momento, não poder ter contato e/ou sair com amigos, e esses fatores interferem de forma direta na saúde desses trabalhadores, refletidos na insônia, na angústia, na ansiedade, dores de cabeça entre outros que se apresentam de forma sutil sinalizando o adoecimento mental desses profissionais (Fundação Oswaldo Cruz, 2019). 
Destaca-se ainda, que durante toda a pesquisa os trabalhadores do CAPS não associaram adoecimento mental ao fato de estarem inseridos em um equipamento de saúde mental, mas, reconhecem o quanto a pandemia e o isolamento social trouxeram impactos psicossociais que reverberaram sim na sua saúde mental.

\section{Considerações finais}

A saúde mental dos trabalhadores da área da saúde tem sido temática recorrente nas pesquisas, das quais utilizamos para debater este estudo, e tem se tornado imprescindível problematizar como esses profissionais estão lidando com o autocuidado frente a sua rotina de trabalho. Entende-se que o trabalho tem constituído processos psíquicos dos sujeitos visto que, é um dos âmbitos que mais ocupa espaços cotidianos na vida das pessoas.

Os transtornos mentais e de personalidade já se tornam uma das causas mais comuns de ausência ou afastamento do trabalho, as pessoas estão adoecendo e isso é fato. Logo, trabalhadores da área da saúde mental podem encontrar-se mais suscetíveis ao adoecimento em consequência de acompanharem pessoas com sofrimento psíquico no seu dia a dia na rotina de trabalho. Então, como estes se tornam resilientes e conseguem não se deixar afetar pelo seu trabalho? Esta questão nos aparece como um emblema para pensar novos estudos acerca da temática.

Exercitar o autocuidado dentro e fora do seu ambiente laboral é a forma mais eficaz de manter a saúde mental. Aspectos como o bom convívio com a equipe, trabalho multiprofissional e ambiente acolhedor facilitam esse processo dentro do trabalho. Já fora desse ambiente, atividades de lazer, terapia, convívio com a família e amigos asseguram que essas pessoas se mantenham estáveis mentalmente.
Outro aspecto importante a se destacar, é que esses trabalhadores reconhecem no seu dia a dia as dificuldades para manutenção e realização das suas práticas, porém quando questionados sobre isso nas entrevistas, apresentaram-se receosos, negando-se a responder ou respondendo em divergência do que relatavam no cotidiano do seu trabalho. $O$ que se apresenta como dado importante para futuras pesquisas: quantos trabalhadores não se calam frente as adversidades do trabalho por medo de ser demitido e acabam por adoecer frente a isso? Este analisador, em alguma medida, foi um fator psicossocial observado neste estudo.

Por fim, anseia que esse estudo possa servir de subsídio para as gestões municipais avaliarem e escutarem suas equipes de trabalho, afim de garantir que a saúde do trabalhador seja reconhecida e praticada com maior relevância. Bem como, para o mundo acadêmico, levantando questionamentos que possam ser investigados sendo base para melhorias da saúde do trabalhador no Brasil, tanto na esfera de saúde pública e de políticas públicas.

\section{Contribuições dos autores}

\begin{abstract}
Alves WL participou da concepção, delineamento, busca e análise qualitativa dos dados da pesquisa, interpretação dos resultados, redação do artigo científico. Lavor Filho TL participou da concepção, delineamento, busca e análise qualitativa dos dados da pesquisa, interpretação dos resultados, redação do artigo científico e supervisão final do manuscrito.
\end{abstract}

\section{Conflitos de interesses}

Nenhum conflito financeiro, legal ou político envolvendo terceiros (governo, empresas e fundações privadas, etc.) foi declarado para nenhum aspecto do trabalho submetido (incluindo, mas não se limitando a subvenções e financiamentos, participação em conselho consultivo, desenho de estudo, preparação de manuscrito, análise estatística, etc.). 


\section{Referências}

Alves, V. S. (2009). Modelos de atenção à saúde de usuários de álcool e outras drogas no contexto do centro de atenção psicossocial (CAPSad) [Tese de doutorado, Universidade Federal da Bahia]. https://repositorio.ufba.br/ri/handle/ $\underline{\text { ri/10857 }}$

Azevedo, A., \& Lobo, F. (2013). Prazer e sofrimento no trabalho. Congresso internacional de psicologia do trabalho e das organizações. Universidade Católica

Bottega, C. G., \& Merlo, A. C. (2017). Clínica do trabalho no SUS: possibilidade de escuta aos trabalhadores. Psicologia \& Sociedade, 29, e156376. https://doi.org/10.1590/1807$\underline{0310 / 2017 v 29156376}$

Campos, M. R. (2017). Trabalho, alienação e adoecimento mental: as metamorfoses no mundo do trabalho e seus reflexos na saúde mental dos trabalhadores. Revista De Políticas Públicas, 2(2), 797-811. http://dx.doi.org/10.18764/21782865.v21n2p797-812

Cordeiro, T. M. S. C., Mattos, A. I. S., Cardoso, M. C. B., Santos, K. O. B., \& Araújo, T. M. (2016). Notificações de transtornos mentais relacionados ao trabalho entre trabalhadores na Bahia: estudo descritivo, 2007-2012. Epidemiologia e Serviços de Saúde, 5(2), 363-72. https://doi.org/10.5123/ S1679-49742016000200015

Dejours, C. (1993). A loucura do trabalho: Estudo de Psicopatologia do Trabalho (5a ed). Cortez.

Demartini, Z. B. F. (1988). Histórias de vida na abordagem de problemas educacionais. In M. R. O. Simson (Org.), Experimentos com histórias de vida (pp. 44-105). Vértice.

Fonseca, R. T. M. (2003). Saúde Mental para e pelo trabalho. Caderno da Escola de Direito e Relações Internacionais da Faculdade do Brasil, 1(2), 73-93. https://portaldeperiodicos. unibrasil.com.br/index.php/cadernosdireito/article/ view/2482

Fundação Oswaldo Cruz. (2019). Saúde Mental e Atenção Psicossocial na Pandemia COVID-19, Recomendações Gerais. Ministério da Saúde. https://www.fiocruzbrasilia.fiocruz. br/wp-content/uploads/2020/04/Sa\%C3\%BAde-Mental-eAten\%C3\%A7\%C3\%A3o-Psicossocial-na-Pandemia-Covid19-recomenda\%C3\%A7\%C3\%B5es-gerais.pdf

Gil, A. C. (2010). Como elaborar projetos de pesquisa (5a. ed.). Atlas.

Gomez, C. M., Vasconcellos, L. C. F., \& Machado, J. M. H. (2018). Saúde do trabalhador: aspectos históricos, avanços e desafios no Sistema Único de Saúde. Ciência \& Saúde Coletiva, 23(6), 1963-1970. https://doi.org/10.1590/141381232018236.04922018
Hirdes, A. (2009). A reforma psiquiátrica no Brasil: uma (re) visão. Ciência \& saúde coletiva, 14(1), 297-305. https://doi. org/10.1590/S1413-81232009000100036

Kauark, F., Manhães, F. C., \& Medeiros, C. H. (2010). Metodologia da pesquisa: guia prático. Via Litterarum.

Lacaz, F. A. C. (2007). O campo Saúde do Trabalhador: resgatando conhecimentos e práticas sobre as relações trabalho saúde. Cadernos de Saúde Pública, 23(4), 757-766. https:// doi.org/10.1590/S0102-311X2007000400003

Lucca, S. R. (2017). Saúde, saúde mental, trabalho e subjetividade. Revista Laborativa, 6 (Edição Especial), 147-159. https://ojs. unesp.br/index.php/rlaborativa/article/view/1626

Marqueze, E. C., \& Moreno, C. R. C. (2005). Satisfação no trabalho - uma breve revisão. Revista brasileira de Saúde Ocupacional, 30(112), 69-79. https://doi.org/10.1590/ S0303-76572005000200007

Melo, C. F., Cavalcante, A. K. S., \& Facanha, K. Q. (2019). Invisibilização do adoecimento psíquico do trabalhador: limites da integralidade na rede de atenção à saúde. Trabalho, Educação e Saúde, 17(2), e0020132. https://doi. org/10.1590/1981-7746-sol00201

Ministério da Saúde. (2020). Corona Vírus- COVID-19: O que você precisa saber. https://www.gov.br/saude/pt-br/ coronavirus/como-se-proteger

Oliveira, G. S., Monteiro, L. S., Carvalho, M. F. A. A., \& Freire, A. K. S. (2020). Saúde Mental em tempos da Pandemia da COVID-19: Concepções dos trabalhadores da Atenção Primaria a Saúde. Research, Society and Development, 9(10), e9449109339. http://dx.doi.org/10.33448/rsd-v9i10.9339

Pinho, P., Oliveira, M. A., \& Almeida, M. M. (2008). A reabilitação psicossocial na atenção aos transtornos associados ao consumo de álcool e outras drogas: uma estratégia possível? Archives of Clinical Psychiatry, 35(1), 82-88. https:// doi.org/10.1590/S0101-60832008000700017

Portaria n. 1679, de 19 de setembro de 2002. (2002). Dispõe sobre estruturação da rede nacional de atenção integral à saúde do trabalhador no SUS e dá outras providências. https://bvsms.saude.gov.br/bvs/saudelegis/gm/2017/ MatrizesConsolidacao/comum/13614.html

Portaria $n^{\circ} 3.088$, de 23 de dezembro de 2011. (2011). Institui a Rede de Atenção Psicossocial para pessoas com sofrimento ou transtorno mental e com necessidades decorrentes do uso de crack, álcool e outras drogas, no âmbito do Sistema Único de Saúde (SUS). https://bvsms.saude.gov. br/bvs/saudelegis/gm/2011/prt3088_23_12_2011_rep.html 
Resende, D. A. (2019). Acidente de trabalho com os servidores da Secretaria de Educação da Prefeitura Municipal de Uberlândia [Dissertação de mestrado, Universidade Federal de Uberlândia]. Repositório UFU. http://doi. org/10.14393/ufu.di.2020.93

Ribeiro, M. C. (2015). Trabalhadores dos Centros de Atenção Psicossocial de Alagoas: interstícios de uma nova prática. Interface - Comunicação Saúde Educação, 19(52), 95-107. https://doi.org/10.1590/1807-57622014.0151

Ribeiro, M. C., Barros, A. C., Correia, M. S., Lessa, R. O., Tavares, L. N., \& Chaves, J. B. (2018). Atenção psicossocial e satisfação no trabalho: processos dialéticos na saúde mental. Revista Interdisciplinar de Estudos em Saúde, 7(1) 55-67. https://doi. org/10.33362/ries.v7i1.1102
Silva, J. L. L. D., Soares, R. D. S., Costa, F. D. S., Ramos, D. D. S., Lima, F. B., \& Teixeira, L. R. (2015). Fatores Psicossociais e prevalência da Sindrome de Burnout entre trabalhadores de enfermagem intensivistas. Revista Brasileira de Terapia Intensiva, 27(2). https://doi.org/10.5935/0103507X.20150023

Vieira, J. K. S., Carvalho, R. N., Azevedo, E. B., S., Priscilla, M. C., \& Ferreira Filha, M. O. (2010). Concepção sobre drogas: relatos dos usuários do CAPS-ad, de Campina Grande, PB. Revista eletrônica saúde mental álcool e drogas, 6(2), 274-295. http://pepsic.bvsalud.org/scielo.php?script=sci arttext\&pid=S1806-69762010000200004\&lng=pt\&tlng=pt

Wetzel, C., Kantorski, L. P., \& Souza, J. (2008). Centro de Atenção Psicossocial: trajetória, organização e funcionamento. Revista de Enfermagem da UERJ, 16(1), 39-45. http://hdl. handle.net/10183/107164 